\title{
Estabilidade Térmica de Embalagens de Poli (Tereftalato de Etileno (PET): Determinação de Oligômeros.
}

\author{
Maria Teresa de A. Freire, Felix G. R. Reyes e Laurence Castle
}

Resumo: Embalagens plásticas para alimentos contendo poli(tereftalato de etileno (PET) foram submetidas a diversas condições de aquecimento. Oligômeros foram identificados por cromatografia líquida de alta eficiência acoplada à espectrometria de massas, quantificados e usados como parâmetro de avaliação da estabilidade térmica do PET. Pequenas variações foram verificadas na distribuição dos oligômeros unicamente nas amostras aquecidas a $230{ }^{\circ} \mathrm{C}$, o que sugere estabilidade térmica do PET nas condições de aquecimento utilizadas. Os resultados obtidos indicam que o uso do polímero é adequado para utilização como material de embalagem para alimentos a serem aquecidos em fornos convencionais ou de microondas.

Palavras-chave: Polietileno tereftalato, embalagem, migração, estabilidade térmica.

\section{Introdução}

O poli(tereftalato de etileno (PET) tem sido, nos últimos anos, largamente utilizado como material de embalagem para alimentos. O PET é utilizado tanto na forma de garrafas para bebidas carbonatadas, bebidas alcoólicas e óleos vegetais ${ }^{[1]}$, como na forma de filme simples ou laminado com outros materiais para os mais variados tipos de produtos alimentíci${ }{ }^{[2]}$. O sucesso da aplicação do PET deve-se às suas propriedades físico-mecânicas, como rigidez, brilho, estabilidade térmica, estabilidade à luz, assim como propriedades de barreira a gases ${ }^{[3,4]}$.

Uma das mais recentes aplicações do PET, encontra-se no mercado de produtos de conveniência, especialmente refeições semi-prontas, onde a embalagem é retirada do congelador e aquecida diretamente em forno convencional ou de microondas ${ }^{[5]}$. Para esta aplicação específica, a embalagem pode ser exposta a temperaturas que variam entre $-40{ }^{\circ} \mathrm{C}$ a $220{ }^{\circ} \mathrm{C}^{[3,6,7]}$. Dados da literatura apontam que embalagens de cartão laminadas com PET suportam temperaturas de $220^{\circ} \mathrm{C}$ por um período de até 35 minutos, tempo suficiente para que uma refeição esteja totalmente aquecida $^{[7]}$.

Características de crocância e escurecimento, desejáveis para alguns produtos alimentícios, na maioria das vezes, não são obtidas em fornos de microondas. Com o propósito de superar esta deficiência na utilização do forno de microondas, introduziu-se no mercado o "susceptor", que é um material basicamente formado de PET metalizado com alumínio ${ }^{[5,8,9]}$. Este material transforma a energia proveniente da radiação microondas em calor, causando desidratação superficial do alimento, produzindo crocância e escurecimento $^{[8]}$. As principais embalagens encontra-

Maria T. de A. Freire e Felix G. R. Reyes, Departamento de Ciência de Alimentos, Faculdade de Engenharia de Alimentos, Universidade Estadual de Campinas - UNICAMP, Caixa postal 6121, CEP 13081-970, Campinas, SP. Laurence Castle, Ministry of Agriculture, Fisheries and Food, Food Science Laboratory, Colney Lane, Norwich NR4 7UQ, United Kingdom 
das no mercado que utilizam "susceptors" destinamse a pizza, pipoca e batatas fritas ${ }^{[10]}$.

Assim como para qualquer material em contacto com alimentos, o uso seguro do PET é baseado em dois aspectos: no nível esperado de migração de componentes da embalagem para o alimento e nas propriedades toxicológicas dos mesmos.

Estudos de migração realizados com PET concentram-se, principalmente, em oligômeros, por serem estes os principais componentes identificados nos extratos não voláteis extraídos do polímero. Ressalta-se, ainda, que estudos em que embalagens de PET são submetidas a altas temperaturas, têm recebido destaque, pois as concentrações de oligômeros encontradas tem superado, em alguns casos, os limites estabelecidos em regulamentações que normatizam o nível de contaminantes de embalagens em alimentos ${ }^{[11-13]}$. Alimentos gordurosos são os mais susceptíveis à migração de oligômeros, onde níveis de até $160 \mathrm{mg} / \mathrm{dm}^{2}$ do trímero cíclico foram encontrados em óleo de milho quando o PET foi aquecido em forno de microondas ${ }^{[11]}$, excedendo os limites de migração global de $8 \mathrm{mg} / \mathrm{dm}^{2}$ e $10 \mathrm{mg} /$ $\mathrm{dm}^{2}$ estabelecidos pelo MERCOSUL ${ }^{[14]}$ e pela União Européia $^{[15]}$, respectivamente. Tem sido verificado, ainda, que a taxa de migração é influenciada tanto pela temperatura como pelo tempo de aquecimento ${ }^{[11-13]}$.

Não há na literatura dados disponíveis sobre a toxicidade crônica dos oligômeros do PET. Todavia, estudos de toxicidade aguda com extratos de PET, realizados em ratos, via intubação gástrica, apresentaram valores de Dose Letal $50\left(\mathrm{DL}_{50}\right)$ acima de $10.000 \mathrm{mg} / \mathrm{kg} \mathrm{pc} .^{[16]}$

Paralelamente à tendência do crescimento da utilização de artigos plásticos para contato com alimentos, surge a necessidade de um reaproveitamento, economicamente viável, com o propósito de evitar o acúmulo destes materiais no ambiente ${ }^{[4,17-20]}$. A maior barreira para a utilização de plásticos reciclados para contato com alimentos está diretamente relacionada com a proteção do consumidor, que pode estar sujeito à exposição de substâncias tóxicas devido a processos de migração de componentes das embalagens para os alimentos. Tais contaminantes, em materiais reciclados, podem ter origem da remoção incompleta de resíduos de alimentos, bem como do mau uso da embalagem por parte do consumidor antes da realização da reciclagem. Além disso, contaminantes podem ser formados durante a utilização doméstica do material, bem como durante o processo de reciclagem, como resultado da degradação térmica tanto do material de embalagem, como de aditivos incorporados ao mesmo ${ }^{[21]}$.
Estudos sobre a estabilidade térmica do PET indicam a formação de ésteres vinílicos e de grupos carboxílicos terminais como produtos de degradação ${ }^{[22,23]}$. Outras consequiências da degradação observadas incluem descoloração, formação de substâncias voláteis (acetaldeído e dióxido de carbono, principalmente), formação de anidridos, de ácido tereftálico e de oligômeros ${ }^{[22,23]}$. A presença de resíduos de catalisadores, bem como moléculas de dietileno glicol ao longo da cadeia polimérica, influenciam a taxa e processo de degradação do PET $^{[23]}$.

Tendo em vista a importância da aplicação do polietileno tereftalato como material de embalagem para produtos alimentícios submetidos a altas temperaturas, este trabalho teve por objetivo avaliar a estabilidade térmica do polímero através do estudo dos oligômeros.

\section{Material e Métodos}

\section{Material}

Embalagens de PET foram coletadas no mercado consumidor de Campinas, SP, Brasil e em Norwich, Reino Unido. As amostras incluíram garrafas de PET, sacos plásticos de PET destinados a fornos convencionais e de microondas ("roasting bags"), PET metalizado com alumínio destinado a fornos de microondas ("susceptor"), bandejas de papel cartão revestidas com PET e laminados de PET com estrutura básica de PET/PEBD*.

Solventes grau HPLC (água, cloreto de metileno, acetonitrila e metanol) e solventes grau analítico (ácido acético) foram obtidos de Rathburns (Walkerburn, UK). Hexafluoropropan-2-ol (HFIP), N,N-dimetil acetamida e todos os outros produtos químicos utilizados foram obtidos de Aldrich Chemical Co. (Gillingham, UK).

\section{Condições de Teste}

As amostras de PET foram submetidas a altas temperaturas de acordo com as condições descritas na Tabela 1. Bandejas, filmes multi-camada delaminados manualmente e "roasting bags" foram consideradas embalagens para utilização em temperaturas máximas encontradas em fornos convencionais e de microondas ${ }^{[3,6,7]}$. Laminados que tiveram

${ }^{*}$ PEBD = polietileno de baixa densidade 
Tabela 1. Condições de aquecimento para amostras de PET

\begin{tabular}{|c|c|c|c|}
\hline Amostra & $\mathrm{T}\left({ }^{\circ} \mathrm{C}\right)$ & Tempo $(\mathrm{min})$ & Fonte \\
\hline Filme multi-camadas delaminados com solvente & 120 & 50 & Campinas - Brasil \\
\hline Garrafas & 150 & 50 & Campinas - Brasil \\
\hline "Roasting bags" & 230 & 50 & $\begin{array}{l}\text { RB } 01 \text { Campinas - Brasil } \\
\text { RB 02-04 Norwich - UK }\end{array}$ \\
\hline Filmes multi-camadas delaminados manualmente & 230 & 50 & Campinas - Brasil \\
\hline Bandejas delaminadas & 230 & 50 & Campinas - Brasil \\
\hline
\end{tabular}

suas camadas removidas com solvente foram aquecidas em temperaturas abaixo do ponto de fusão do PEBD. Garrafas foram aquecidas em temperaturas acima do ponto de ebulição da água, tomando-se por hipótese esta condição como aplicável em etapas de lavagem e secagem do polímero em processos de reciclagem secundária de materiais plásticos.

\section{Análise de Oligômeros}

O trímero cíclico foi extraído de pellets de PET, conforme metodologia descrita por Freire et al ${ }^{[24]}$, para posterior utilização como padrão externo na quantificação de oligômeros.

A extração dos oligômeros foi realizada dissolvendo-se $0,1 \mathrm{~g}$ de PET em $10 \mathrm{~mL}$ de HFIP/cloreto de metileno $(3: 7 \mathrm{v} / \mathrm{v})$ e precipitando-se o polímero de alta massa molar em acetona. Os solventes foram evaporados e o resíduo diluído em $\mathrm{N}, \mathrm{N}$ dimetil acetamida ${ }^{[25]}$. A identificação dos oligômeros foi realizada através de cromatografia líquida acoplada à espectrometria de massas (espectro de massas Fisons Instruments, Manchester, UK e detector UV Spectroflow (254 nm) Kratos, Manchester, UK), conforme descrito por Freire et $a l^{[22]}$. Para a quantificação por CLAE (injetor tipo Rheodyne $(20 \mu \mathrm{L})$, cromatógrafo PYE UNICAM PU 4025 e) com detecção por UV (254 nm), utilizou-se uma coluna Hichrom S5 C8 (250 x 4,6 mm). Utilizou-se eluição por gradiente com solvente A composto de águaacetonitrila-ácido acético (85:15:0,25 v/v/v) e solvente B composto de acetonitrila-água ( $85: 15 \mathrm{v} / \mathrm{v})$. Utilizouse programação linear com fluxo de $1,5 \mathrm{~mL} / \mathrm{min}$ : de 5 a $60 \%$ de B em 8 min, de 60 a $70 \%$ de B em 9 min, $100 \%$ de $\mathrm{B}$ por $10 \mathrm{~min}$, de 100 a $5 \%$ de B em $1 \min ^{[25]}$.

\section{Resultados e Discussão}

Em todas as amostras de PET foi verificada a presença de oligômeros cíclicos de primeira e segunda série, bem como de oligômeros alicíclicos da segunda série. Na Figura 1 é apresentado um cromatograma típico da separação dos mesmos. Para todas as amostras, o trímero cíclico foi o oligômero predominante, seguido pelo tetrâmero, pentâmero e hexâmero. Concentrações menores de oligômeros alicíclicos da segunda série também foram quantificados (dímero a tetrâmero). Os oligômeros de segunda série apresentam um acréscimo de 44 unidades de massa em relação aos respectivos oligômeros da primeira série, resultante da substituição de uma molécula de etileno glicol (MEG) por uma molécula de dietileno glicol (DEG). "Roasting bags" apresentaram a maior concentração de trímero cíclico comparada às demais categorias de amostras analisadas.

A Figura 2 mostra a distribuição dos oligômeros em garrafas de PET antes e após aquecimento a $150{ }^{\circ} \mathrm{C}$. Verificou-se que não houve diferença significativa $(\mathrm{p}<0,05)$, na concentração de oligômeros

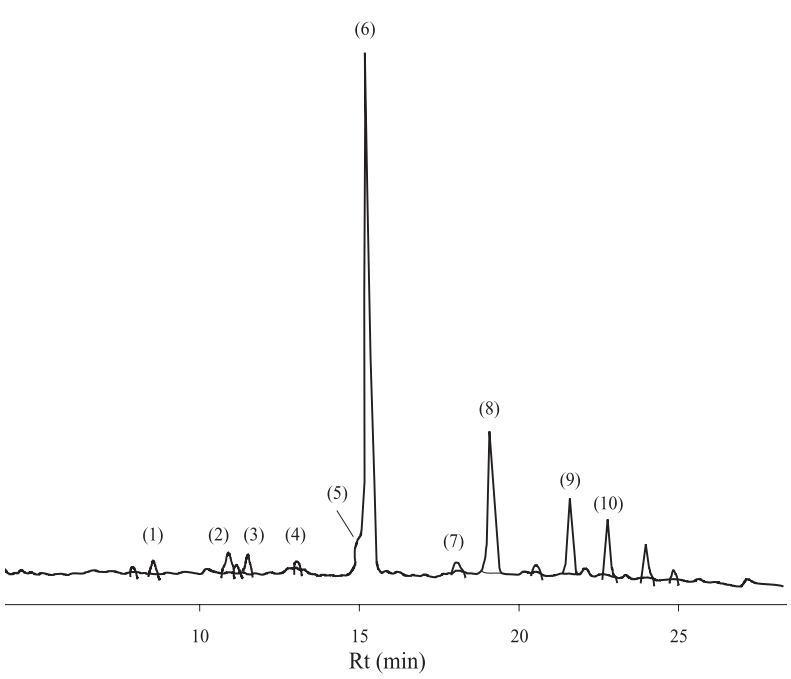

Figura 1. Cromatograma típico da separação de oligômeros do PET por CLAE. (1) dímero alicíclico da segunda série, (2) trímero alicíclico da segunda série, (3) dímero cíclico da segunda série, (4) tetrâmero alicíclico da segunda série, (5) trímero cíclico da segunda série, (6) trímero cíclico, (7) tetrâmero cíclico da segunda série, (8) tetrâmero cíclico, (9) pentâmero cíclico, (10) hexâmero cíclico. 


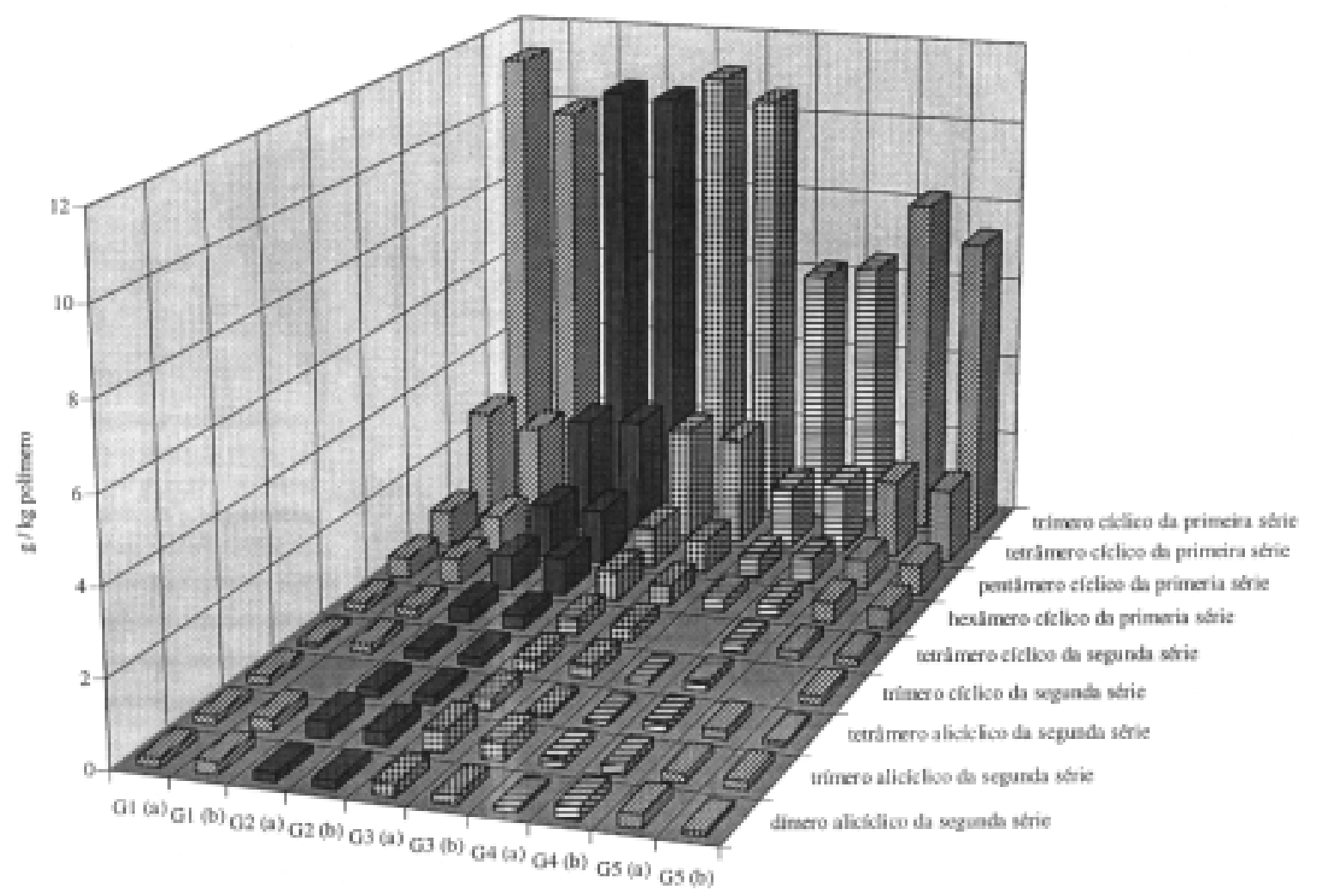

Figura 2. Efeito da temperatura na distribuição de oligômeros para amostras de garrafas de PET (G1 a G5). (a) amostra não aquecida, (b) aquecimento a $150{ }^{\circ} \mathrm{C} / 50 \mathrm{~min}$

totais nas garrafas aquecidas a $150{ }^{\circ} \mathrm{C}$ em relação à concentração inicialmente presente nestas amostras (Tabela 2). Estes resultados indicam que o PET é estável nessa condição de aquecimento.

Na Figura 3 estão apresentados os resultados relativos ao efeito do aquecimento, a $120^{\circ} \mathrm{C}$, sobre os oligômeros de PET extraídos de filmes multi-camadas. Verificou-se que não houve diferença significativa $(\mathrm{p}<0,05)$, na concentração de oligômeros totais nos laminados de PET aquecidos a $120^{\circ} \mathrm{C}$, em relação à concentração inicialmente presente nestas amostras, confirmando a boa estabilidade do PET a temperaturas inferiores a $150{ }^{\circ} \mathrm{C}$ (Tabela 2).

$\mathrm{O}$ efeito do aquecimento, a $230{ }^{\circ} \mathrm{C}$, sobre os oligômeros do PET para bandejas, filmes delaminados, "roasting bags" e "susceptors" está apresentado nas Figuras 4 e 5 . A esta temperatura verificou-se alteração no nível de oligômeros, sendo que a maior contribuição para esta alteração foi o aumento de concentração do dímero, trímero e tetrâmero alicíclicos da segunda série. Verificou-se diferença significativa ( $\mathrm{p}<0,05)$, entre os oligômeros totais determinados antes e após o aquecimento em uma das amostras delaminadas (DL3), duas de "roasting bags" (RB1, RB2), e no "susceptor" (S1) (Tabela 2).
Estes resultados sugerem a ocorrência de degradação térmica, com despolimerização da cadeia principal do polímero, para estas amostras. A diminuição na concentração do pentâmero e hexâmero cíclicos observada nas amostras aquecidas a $230{ }^{\circ} \mathrm{C}$ sugere ainda, degradação dos oligômeros cíclicos inicialmente presentes.

A formação de oligômeros ocorre durante o processo de polimerização do PET $^{[26]}$ e tem-se comprovado que a concentração destas substâncias aumenta durante o processo de extrusão ${ }^{[23]}$.

$\mathrm{O}$ mecanismo pelo qual ocorre o aumento na formação de oligômeros cíclicos durante o processo de degradação oxidativa do PET, ainda não é esclarecido. Entretanto, tem sido associado à despolimerização aleatória da cadeia principal por mecanismo de radicais livres ${ }^{[23]}$.

Os resultados obtidos permitem discutir sobre aspectos relacionados ao possível reaproveitamento de embalagens pós-consumo pelo processo de reciclagem secundária. Este processo abrange etapas de identificação e separação de diferentes polímeros, moagem, lavagem, secagem, aglutinação, extrusão, peletização e transformação em um novo artefato ${ }^{[21]}$. A manutenção dos níveis de oligômeros totais (Ta- 


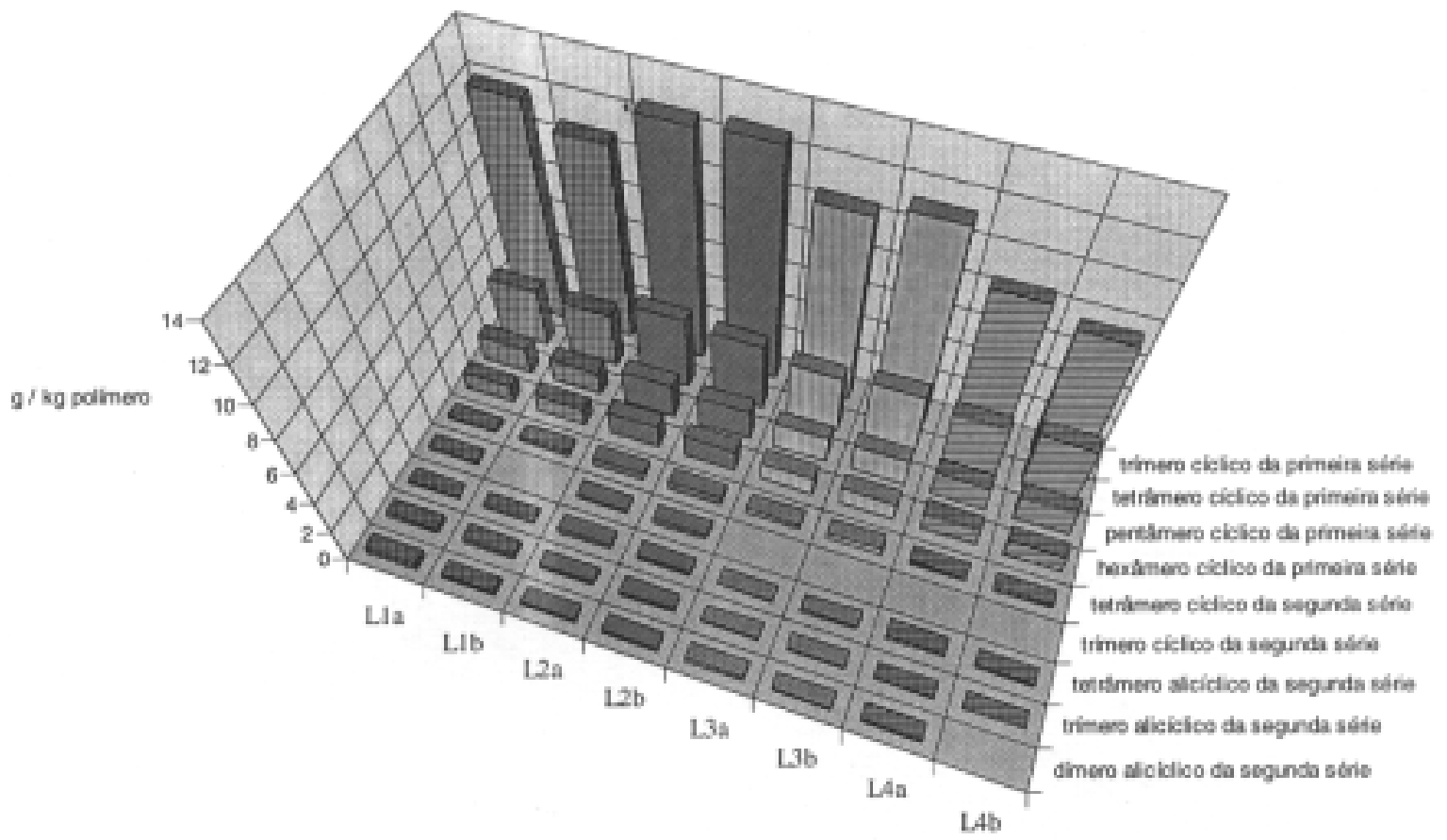

Figura 3. Efeito da temperatura na distribuição de oligômeros de filmes multi- camadas de PET (L1 a L4). (a): amostra não aquecida, (b) aquecimento a $120{ }^{\circ} \mathrm{C} / 50 \mathrm{~min}$.

bela 2), assim como dos oligômeros individuais (Figuras 2 a 4) nas amostras de PET aquecidas a temperaturas inferiores a $230{ }^{\circ} \mathrm{C}$, é uma informação importante para etapas de secagem, onde temperaturas de $135^{\circ} \mathrm{C}$ a $180^{\circ} \mathrm{C}$ podem ser utilizadas para que o conteúdo de umidade atinja valores iguais ou inferiores a $0,002 \%{ }^{[27]}$. Quando a umidade é superior a $0,02 \%$, as propriedades físicas do PET podem ser al- teradas, especialmente a viscosidade intrínseca que pode ser seriamente reduzida durante o processo de extrusão ${ }^{[27]}$.

$\mathrm{O}$ aumento na concentração de oligômeros observado a temperaturas de $230{ }^{\circ} \mathrm{C}$, sugere que cuidados adicionais devem ser tomados durante o processo de extrusão, onde temperaturas superiores à temperatura de fusão do PET $\left(260{ }^{\circ} \mathrm{C}\right)$ são empregadas.

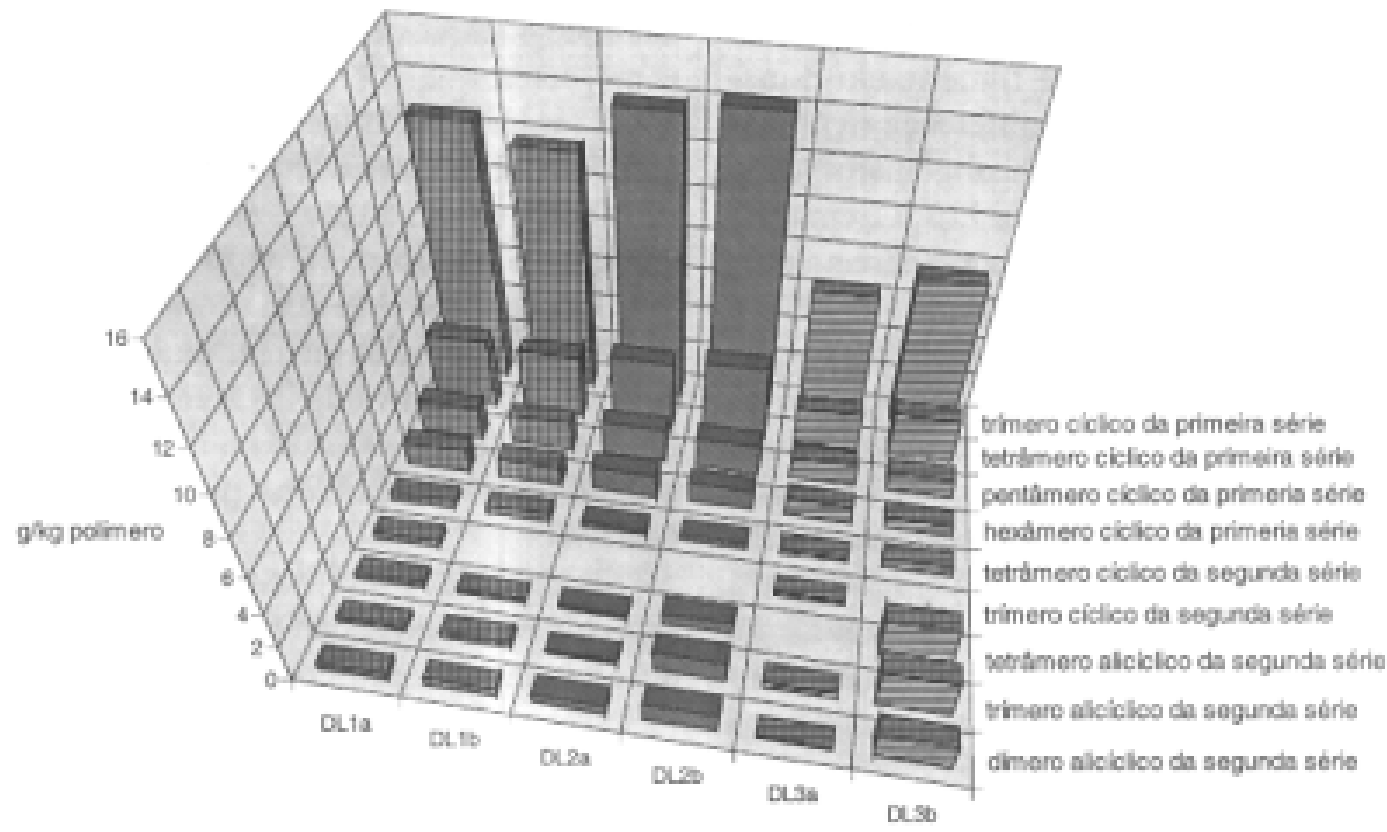

Figura 4. Efeito da temperatura na distribuição de oligômeros de filmes multi-camadas delaminados de PET (DL1 a DL3). (a): amostra não aquecida, (b) aquecimento a $230^{\circ} \mathrm{C} / 50 \mathrm{~min}$. 
Tabela 2. Concentração dos oligômeros totais $(\mathrm{g} / \mathrm{kg}$ ) para amostras de PET antes e após aquecimento a diferentes temperaturas, durante 50 minutos. (a) Valor médio de 4 determinações, (b) $\mathrm{s}_{\mathrm{A}}=$ estimativa de desvio padrão absoluto.

\begin{tabular}{|c|c|c|c|}
\hline \multirow[t]{2}{*}{ Amostra } & \multirow[t]{2}{*}{$\mathrm{T}\left({ }^{\circ} \mathrm{C}\right)$} & \multicolumn{2}{|c|}{ Valor Médio ${ }^{\mathrm{a}}\left(\mathrm{S}_{\mathrm{A}}\right)^{\mathrm{b}}$} \\
\hline & & antes do aquecimento & após aquecimento \\
\hline \multicolumn{4}{|l|}{ Garrafas } \\
\hline G1 & 150 & $17 \pm 1$ & $15 \pm 1$ \\
\hline G2 & 150 & $17 \pm 1$ & $16 \pm 1$ \\
\hline G3 & 150 & $17 \pm 1$ & $16 \pm 1$ \\
\hline G4 & 150 & $9 \pm 0$ & $9 \pm 1$ \\
\hline G5 & 150 & $12 \pm 1$ & $11 \pm 0$ \\
\hline \multicolumn{4}{|l|}{ Filmes multi-camadas } \\
\hline L1 - PET/imp./met./adesivo/PEBD pigm. & 120 & $19 \pm 1$ & $17 \pm 0$ \\
\hline L2 - PET/imp./met./adesivo/PEBD & 120 & $21 \pm 2$ & $21 \pm 1$ \\
\hline L3 - PET/imp./met./PEBD pigm. & 120 & $18 \pm 1$ & $19 \pm 0$ \\
\hline L4 - verniz/imp./PET/met./adesivo/PEBD & 120 & $15 \pm 2$ & $14 \pm 1$ \\
\hline DL1 - Cartão/adesivo/PET & 230 & $21 \pm 2$ & $19 \pm 1$ \\
\hline DL2 - PET/adesivo/alumínio/PEBD & 230 & $22 \pm 3$ & $23 \pm 2$ \\
\hline DL3 - Cartão/adesivo/PET & 230 & $11 \pm 1$ & $18 \pm 0$ \\
\hline \multicolumn{4}{|l|}{ Roasting bags } \\
\hline RB1 & 230 & $24 \pm 1$ & $30 \pm 3$ \\
\hline $\mathrm{RB} 2$ & 230 & $24 \pm 1$ & $33 \pm 1$ \\
\hline RB3 & 230 & $30 \pm 1$ & $33 \pm 4$ \\
\hline RB4 & 230 & $28 \pm 2$ & $27 \pm 3$ \\
\hline \multicolumn{4}{|l|}{ Susceptor } \\
\hline S1 & 230 & $23 \pm 1$ & $30 \pm 3$ \\
\hline
\end{tabular}

É importante salientar que além dos fatores mencionados, o tempo de aquecimento durante a etapa de secagem, bem como temperatura e tempo de resi-

dência na extrusora, são fatores que também influenciam a establidade térmica do PET durante o processo de reciclagem secundária ${ }^{[28]}$.

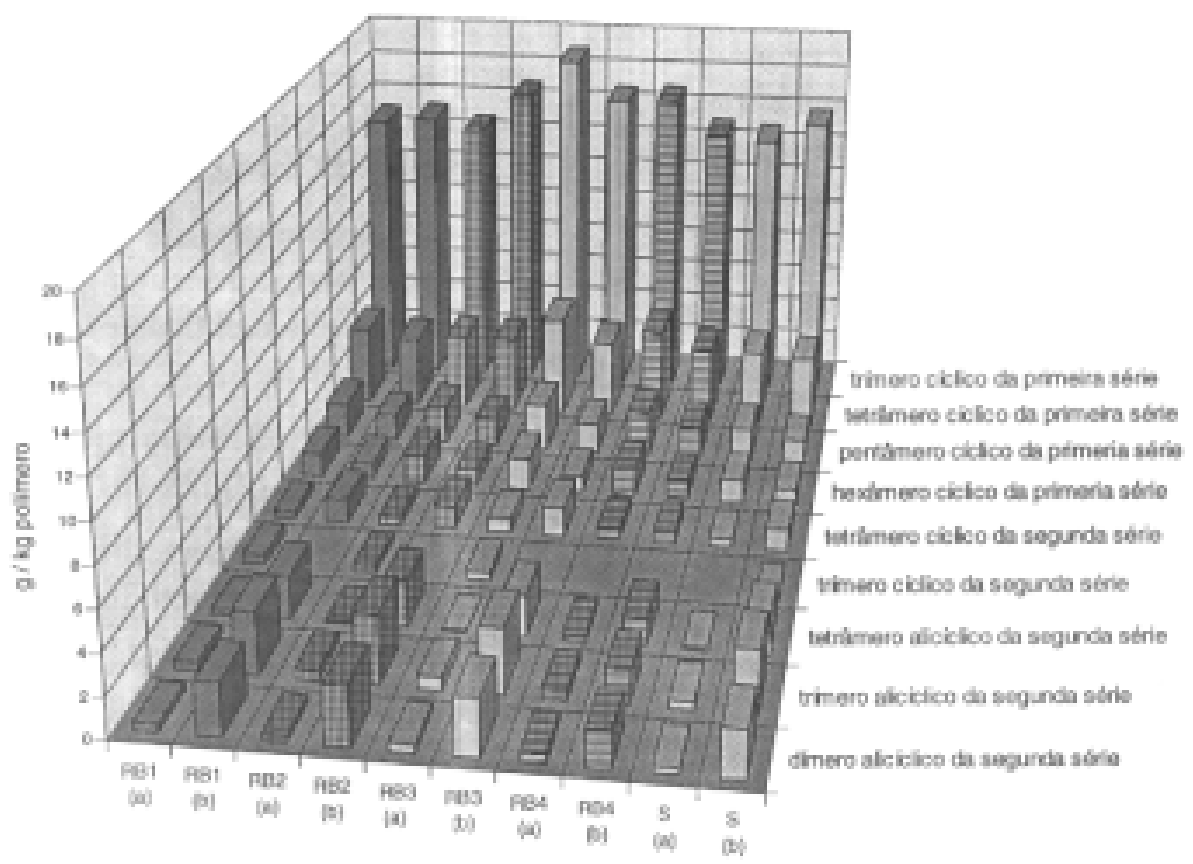

Figura 5. Efeito da temperatura na distribuição de oligômeros em amostras de "roasting bags" (RB1 a RB4) e susceptor (S): (a) amostra não aquecida, (b) aquecimento a $230^{\circ} \mathrm{C} / 50 \mathrm{~min}$. 


\section{Conclusão}

Os resultados obtidos sugerem que o PET é estável quando aquecido a temperaturas abaixo de $230{ }^{\circ} \mathrm{C}$, durante 50 minutos, o que indica que embalagens de PET são adequadas para aquecimento de alimentos em fornos convencionais e de microondas $\left(220^{\circ} \mathrm{C}\right)$.

A estabilidade apresentada pelo PET em relação à composição de oligômeros, quando aquecido nas condições estudadas sugere ainda, que o polímero pós-consumo é adequado para processos de reciclagem secundária, desde que as condições de reprocessamento sejam devidamente controladas, no sentido de evitar um aumento de degradação termomecância do polímero.

\section{Agradecimentos}

Os autores agradecem ao "Conselho Nacional de Desenvolvimento Científico e Tecnológico - CNPq", Brasil e à "Coordenação de Aperfeiçoamento de Pessoal de Nível Superior" - CAPES, Brasil, pela Bolsa de Estudos concedida à Maria Teresa de A. Freire.

\section{Referências Bibliográficas}

1. Ott, D.B.; Trends in food packaging, Journal of Home Economics, 80 (3), 36-43, (1988).

2. Freire, MT. de A. e Reyes, F.G.R.; A importância do polietileno tereftalato (PET) na indústria de embalagens para alimentos. Boletim da Sociedade Brasileira de Ciencia e Tecnologia de alimentos, no prelo.

3. Goddard, K.; The potential of PET. Food Manufacture, September, 22-25, (1986).

4. Holton, E.E.; Asp, E.H. e Zottola, E.A.; Food packaging trends in the 1990s: A consumer and environmental update. Cereal Foods World, 40 (7), 491-493, (1995).

5. Anon - The technology behind ready to eat foods. Food Engineering International, 16 (1), 38-42 (1991).

6. Goddard, R. - Packaging for the microwave. Food Manufacture, November, 29-33 (1986).

7. Honnor, R. - Board benefits. Food Processing, UK, February, 57 (2), 33, 34, 37, (1988).
8. Rubbright, H.A. - Packaging for microwave foods. Cereal Foods World, 35 (9), 927-930, (1990).

9. Poindexter, K. - Innovations in paperboard packaging. Cereal Foods World, 40 (7), 479-481, (1995).

10. Sheridan, L.A. - New wave plastic packaging. Microwave World, 8 (4), 5-9, (1987).

11. Begley, T.H.; Dennison, J.L. \& Hollifield, H.C. Migration into food of polyethylene terephthalate (PET) cyclic oligomers from PET microwave susceptor packaging. Food Additives and Contaminants, 7 (6), 797-803, (1990).

12. Begley, T.H. \& Hollifield, H.C. - Migration of dibenzoate plasticizers and polyethylene terephthalate cyclic oligomers from microwave susceptors packaging into food-simulating liquids and food. Journal of Food Protection, 53 (12), 1062-1066, (1990).

13. Castle, L.; Jickells, S.M.; Gilbert, J. \& Harrison, N. - Migration testing of plastics and microwaveactive materials for high temperature food-use applications. Food Additives and Contaminants, 7 (6), 779-796, (1990).

14. MERCOSUL Disposições gerais para embalagens e equipamentos plásticos em contato com alimentos. Resolução 56/92 do Grupo Mercado Comum, Montevidéo, (1992).

15. EEC, 1990, Commission Directive 90/128/EEC of 23 February relating to plastics materials and articles intended to come into contact with foodstuffs. Official Journal of European Communities, L349, 26-47.

16. ILSI - International Life Sciences Institute Refillable Plastic Packaging made from PET (polyethylene terephthalate). Washington DC, , 131p., c (1993).

17. Anon - Packaging waste management. Food Technology, 44 (7), 98-101, (1990).

18. Sloan, A.E. - Consumers, the environment, and the food industry. Food Technology, 47 (8), 72-91, (1993).

19- Elliot, L. - Recycling and valorisation. Soft Drinks Management International, June, 22, 24, (1994).

20. Parker, G. - Saving energy in packaging. British Food Journal, 93 (3), 19-22, (1991). 
21. Castle, L. - Recycled and reused plastics for food packaging? Packaging Technology and Science, 7, 291-297, (1994).

22. Peters, R.H.\& Still, R.H. - Degradation behaviour of polymers, Applied Fibre Science, 2, 355373, (1979).

23. Jabarin, S.A. - Poly (ethylene terephthalate) degradation (chemistry and kinetics). The Polymeric Materials Encyclopedia, CRC Press, Inc, (CD ROM), 20p, (1996).

24. Freire, M.T. de A., Damant, A.P., Castle, L. \& Reyes, F.G.R. - Thermal Stability of polyethylene terephthalate (PET) intended for food contact: oligomers and volatiles. In: Avaliação da estabilidade térmica de embalagens de polietileno tereftalato (PET): estudo dos oligômeros e substâncias voláteis. Tese (Doutor em Ciência de Alimentos), Faculdade de Enge- nharia de Alimentos. Universidade Estadual de Campinas, Campinas, São Paulo. 79-101, (1997).

25. Begley T.H. \& Hollifield, H.C. - Liquid Chromatographic determination of residual reactants and reaction by-products in polyethylene terephthalate. Journal of the Association Analytical Chemistry, 72 (3), 468-470, (1989).

26. Jabarin, S.A. - Poly (ethylene terephthalate) (Chemistry and Preparation). The Polymeric Materials Encyclopedia, CRC Press, Inc, (CD ROM), 13p, (1996).

27. ICI - Imperial Chemical Industries P.L.C. Middlebrough, Melinar - Polyethylene terephthalate, 35p, Catálogo técnico, (1989).

28. Dulio, V.; Po, R.; Borrelli, R.; Guarini, A. \& Santini, C. - Characterization of low-molecular-weight oligomers in recycled poly (ethylene terephthalate). Die Angewandte Makromolekulare Chemie, 225, 109-122, (1995). 